\title{
Anchorage Performance and Interfacial Mechanics Transfer Characteristics of a Composite Anchor Bolt with Different Surface Shape
}

\author{
Jianwei Yue, Anquan Xu, Tingting Yue, Da Song, Kai Zheng \\ School of Civil and Architectural Engineering, Henan University, Kaifeng, China \\ Email: yjwchn@126.com
}

Received 26 October2015; accepted 27 March 2016; published 30 March 2016

Copyright (C) 2016 by authors and Scientific Research Publishing Inc.

This work is licensed under the Creative Commons Attribution International License (CC BY). http://creativecommons.org/licenses/by/4.0/

\section{(c) (i) Open Access}

\begin{abstract}
To solve the deficiency of steel anchor blot in corrosion resistance and flaw of GFRP anchor bolt in fracture resistance, our research group develops a new composite anchor bolt made of steel strands wrapped up with compound fiber resin. To improve the cohesion performance of the composite anchor bolt, pull-out tests of different composite anchor bolts with different groove intervals and depths were made and analyzed. The results show that the pulling resistance of the composite anchor bolt increases with the increase of groove interval and depth, but groove interval and depth have optimal value. Based on elastic mechanics, the cohesion between anchor bolts and anchor bodies and its distribution characteristics caused by axial tension are analyzed and cohesion formula is obtained. By contrast, the experimental result is consistent with the theoretical analysis. Therefore, the surficial change of anchor colts could influence the performance of the composite anchor bolt. The cohesion force and anchorage performance can be improved by changing the surface of anchor bolts. Research results show that the new composite anchor bolt is high-performance material in the civil engineering.
\end{abstract}

\section{Keywords}

Composite Anchor Bolt, Pullout Test, Surficial Shape, Cohesion

\section{Introduction}

In the late 1950s, the GFRP anchor bolt began to be studied and produced. After decades of development, it has

How to cite this paper: Yue, J.W., Xu, A.Q., Yue, T.T., Song, D. and Zheng, K. (2016) Anchorage Performance and Interfacial Mechanics Transfer Characteristics of a Composite Anchor Bolt with Different Surface Shape. Open Journal of Civil Engineering, 6, 217-224. http://dx.doi.org/10.4236/ojce.2016.62020 
been widely applied to correlative fields. For example, the UK has applied MT-J [1] to roadway support in 1990s and the US has researched the cohesion performance of the composite anchor bolt in geotechnical constructions [2]. In 1970s, China began to make use of the GFRP anchor bolt and it had a good application effect in mines of Xuzhou, etc. [3]. The extended and high-strength screw-thread steel resin bolts and prestressed resin anchor bolts [4] have been approved ubiquitously recent years.

The GFRP anchor bolt has a lot of advantages, such as well corrosion resistance and durableness [5], high tensile strength (which is higher than the ordinary rebar), little specific gravity (which is convenient to transport and construct) and a coefficient of thermal expansion which is similar with the concrete. However, the compression resistance and fracture resistance of the GFRP anchor bolt are inferior to the ordinary rebar, and the strength of extension needs to be further enhanced. To improve the performance of the GFRP anchor bolt effectively, composite anchor bolts were made of steel strands which were wrapped up with compound fiber resin. Nevertheless there were some failure phenomena [6]-[8]; for example, the surficial resin was aborted in shear and the joint for anchoring was aborted in tensile during the tensile tests which were conducted by the same anchoring method with ordinary resin rebars because of the high strength of composite anchor bolts. Obviously, the anchoring method of composite anchor bolts still needs some further researches. The study on anchoring performance of composite anchor bolts is conducted to provide a reference for its application to anti-floating or shoring projects.

\section{Experiment on Anchoring Performance}

The anchoring performance of composite anchor bolts is relative to the diameter and shape of the bolts, the thickness and shear strength of the resin, anchoring length, the property of surrounding soil, etc. [9]-[12]. To study the influence factors and analyze the impact of surficial shape on anchoring performance, a series of laboratory experiments were conducted.

\subsection{Method of Experiment}

The mainly experiment equipment is WAW-600CkN Electro-hydraulic servo universal testing machine. Its Maximum tension is $500 \mathrm{kN}$, the largest piston stroke is $250 \mathrm{~mm}$ and clamping range for $13-40 \mathrm{~mm}$. The tensile experiments of composite anchor bolts are controlled by displacement. The loading speed is set to 0.083 $\mathrm{mm} / \mathrm{s}$ and the diameter of the specimen is $20 \mathrm{~mm}$. As shown in Figure 1, the length of test-piece is $400 \mathrm{~mm}$ [13] while the anchorage length is $260 \mathrm{~mm}$. The test-piece is anchored by a $280 \mathrm{~mm}$-long steel tube with spiral grooves. The anchoring agent is blended while conducting the experiment and then pour it into the steel tube evenly to anchor the test-piece.

\subsection{The Impact of Groove Spacing to Anchoring Performance}

The surface of anchor bolts is grooved by a sander to enhance the cohesion between anchor bolt and anchoring agent.

As the materials for the experiment, the diameters of anchor bolts range from $18.64 \mathrm{~mm}$ to $20.40 \mathrm{~mm}$ and the diameters of steel strands inside of anchor bolts are $15.2 \mathrm{~mm}$. The anchor bolts are processed into four types which are different on groove spacing. They respectively are $0 \mathrm{~mm}, 13.25 \mathrm{~mm}, 23.15 \mathrm{~mm}, 33.42 \mathrm{~mm}$ and the depth of the grooves is $4.05 \mathrm{~mm}$, as shown in Figure 2. Three are chosen in each type and there are 12 test-pieces

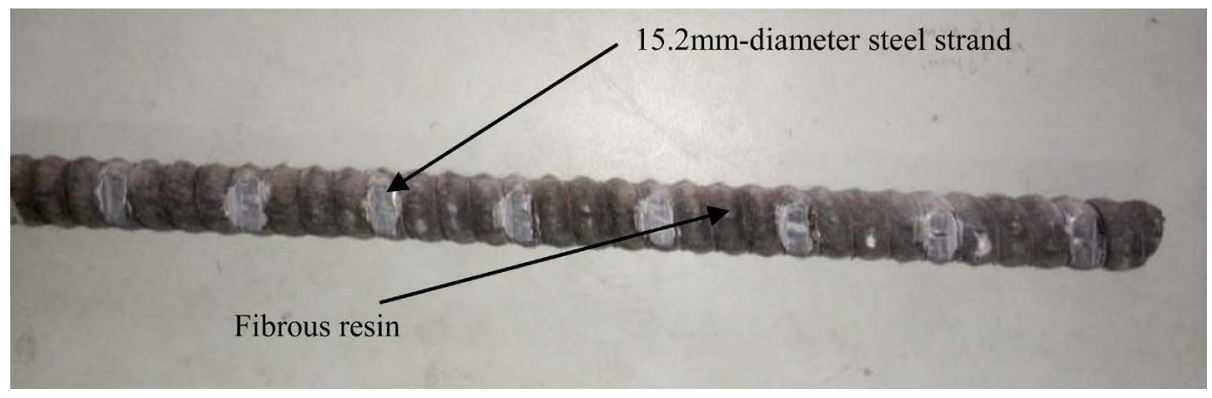

Figure 1. Composite bolt (diameter is $20.4 \mathrm{~mm}$ ). 
in total. The conditions and processing technic of all test-pieces are same. According to the results of experiments, it is turned out that the method of anchoring is reliable and all of the 12 test-pieces are sheared into failure at the interface of anchor bolts and anchoring agent, as shown in Figure 3. The experimental data and the tension-displacement curve are obtained as shown in Table 1 and Figure 4.

As shown in Figure 4, the ultimate tension of type 2 (groove spacing is $13.25 \mathrm{~mm}$ and ultimate tension is $205.9 \mathrm{kN}$ ) is $6.44 \%$ higher than the one of type 1 (groove spacing is $0 \mathrm{~mm}$ and ultimate tension is $193.4 \mathrm{kN}$ ), while the ultimate tension of type 3 (groove spacing is $23.15 \mathrm{~mm}$ and ultimate tension is $201.4 \mathrm{kN}$ ) is $2.20 \%$ lower than the one of type 2. It decreases to $179.2 \mathrm{kN}$ when the groove spacing increases to $33.42 \mathrm{~mm}$ (type 4) and the amplitude of decrease is $12.9 \%$. It is obvious to see the uplift resistance of composite anchor bolts firstly increases and then decreases with the increase of groove spacing.

It can be seen from the failure of the 12 test-pieces that the failure form between anchor bolts and anchoring agent has been changed by the groove spacing. The anchoring agent is aborted in shear before adhesion between

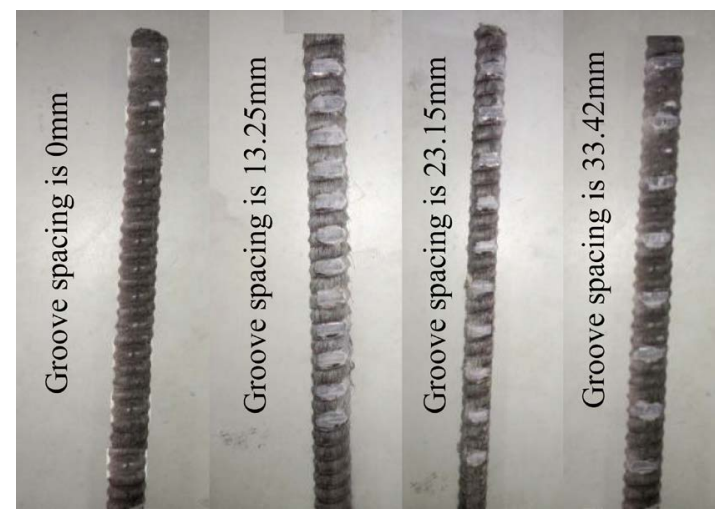

Figure 2. Test-pieces different on groove spacing.

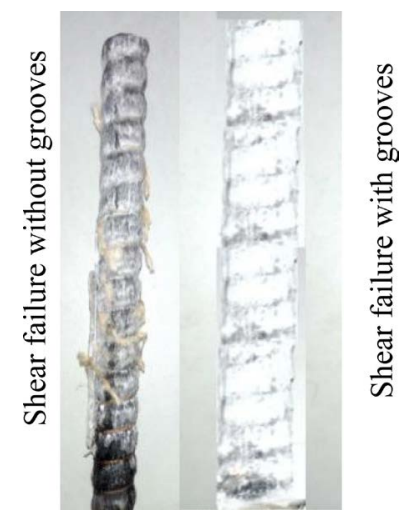

Figure 3. Shear failure.

Table 1. The experimental data of different groove spacing bolts in pull-out test.

\begin{tabular}{ccccccccccccc}
\hline Number & S1 & S2 & S3 & S4 & S5 & S6 & S7 & S8 & S9 & S10 & S11 & S12 \\
\hline Groove spacing/mm & 0 & 0 & 0 & 13.25 & 13.25 & 13.25 & 23.15 & 23.15 & 23.15 & 33.42 & 33.42 & 33.42 \\
Groove depth/mm & 4.05 & 4.05 & 4.05 & 4.05 & 4.05 & 4.05 & 4.05 & 4.05 & 4.05 & 4.05 & 4.05 & 4.05 \\
Bolt diameter/mm & 18.64 & 18.64 & 18.64 & 18.64 & 18.64 & 18.64 & 18.64 & 18.64 & 18.64 & 18.64 & 18.64 & 18.64 \\
& $/ 20.40$ & $/ 20.40$ & $/ 20.40$ & $/ 20.40$ & $/ 20.40$ & $/ 20.40$ & $/ 20.40$ & $/ 20.40$ & $/ 20.40$ & $/ 20.4$ & $/ 20.4$ & $/ 20.4$ \\
Anchorage length/mm & 260 & 260 & 260 & 260 & 260 & 260 & 260 & 260 & 260 & 260 & 260 & 260 \\
Temperature $/{ }^{\circ} \mathrm{C}$ & 22 & 22 & 22 & 22 & 22 & 22 & 22 & 22 & 22 & 22 & 22 & 22 \\
Ultimate tension/KN & 201.1 & 191.9 & 187.3 & 208.1 & 203.6 & 205.9 & 206.2 & 203.6 & 194.5 & 185.3 & 171.6 & 180.7 \\
Ultimate displacement/mm & 12.5 & 9.99 & 11.8 & 11.5 & 14.4 & 15.4 & 18.7 & 16.2 & 19.4 & 21.3 & 21.2 & 22.4 \\
\hline
\end{tabular}




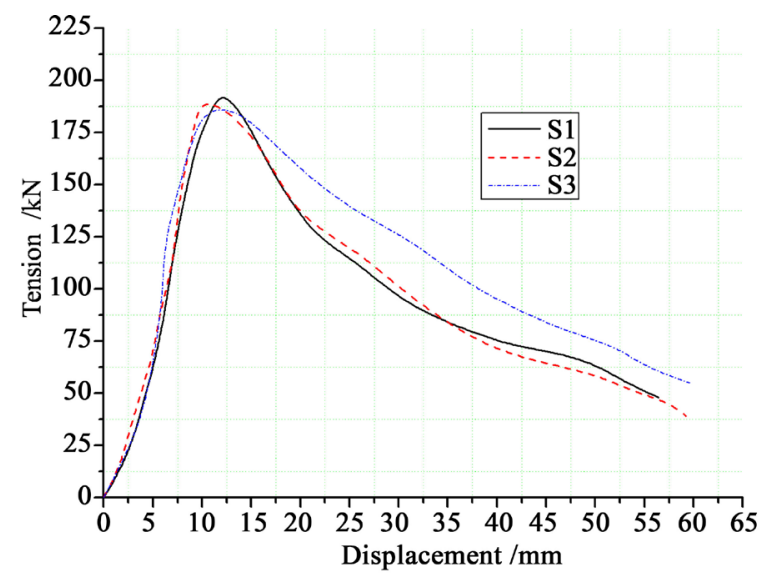

Type 1

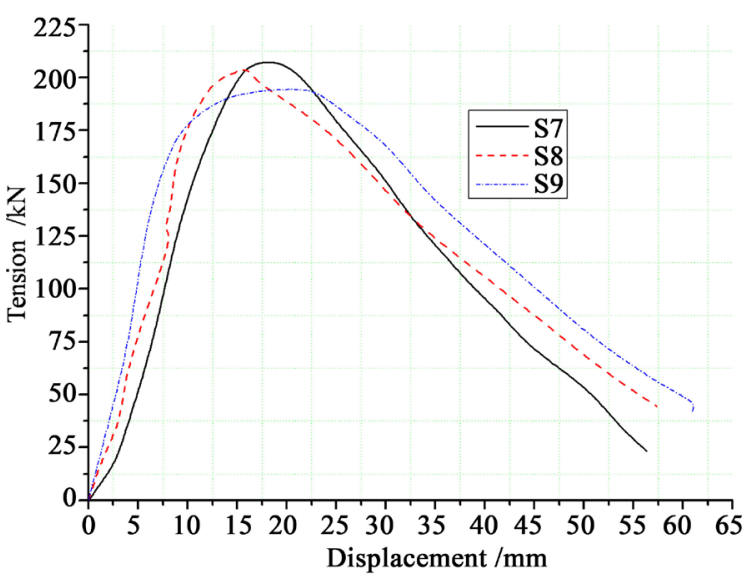

Type 3

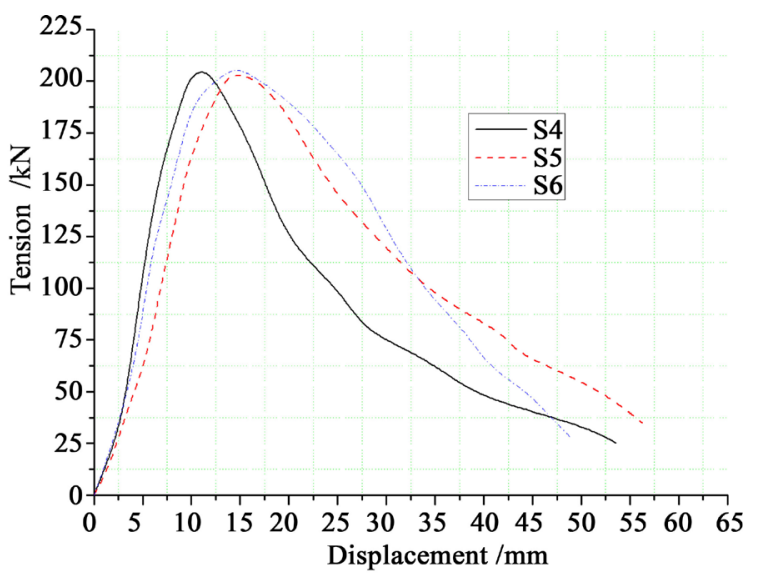

Type 2

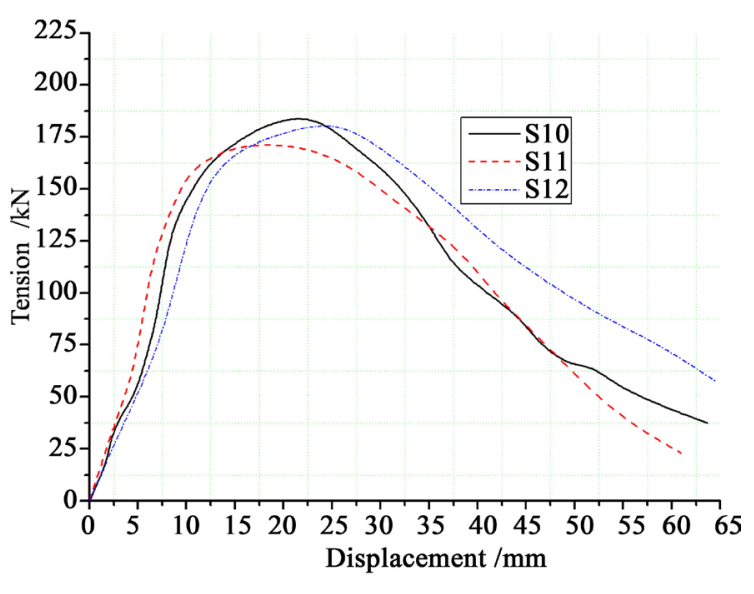

Tvpe 4

Figure 4. The tension-displacement curve of test-pieces with different groove spacing.

anchor bolts and anchoring agent is invalid when the groove spacing is $33.42 \mathrm{~mm}$. It enhances the adhesion effectively that the anchoring agent takes more shear with the decrease of groove spacing. The resin never break away from the inside steel strand during the experiments. It is reasonable that the groove spacing is designed as $23.15 \mathrm{~mm}$ taking various factors into consideration.

\subsection{The Impact of Groove Depth on Anchoring Performance}

It can be researched that the impact of groove depth on anchoring performance based on the above experiment. The anchor bolts are processed into another four types which are different on groove depth. They respectively are $0.88 \mathrm{~mm}, 2.02 \mathrm{~mm}, 3.04 \mathrm{~mm}, 3.95 \mathrm{~mm}$ and the spacing of the grooves is $23.15 \mathrm{~mm}$. Three are chosen in each type and there are 12 test-pieces in total. The conditions and processing technic of all test-pieces are same with the above experiments'. The experimental data, the tension-displacement curve and tension-groove depth are obtained as shown in Table 2, Figure 5 and Figure 6.

When the groove depth is $0.88 \mathrm{~mm}$ the ultimate tension is $182.3 \mathrm{kN}$ which is minimum while the ultimate tension is $208.3 \mathrm{kN}$ which is maximum when the groove depth is $3.95 \mathrm{~mm}$. It is improved $14.3 \%$ by $26.0 \mathrm{kN}$. As shown in Figure 6, the ultimate tension increases with the increase of groove depth.

\section{Mechanical Analysis of the Composite Anchor Bolt}

As we known in material mechanics, the shearing resistance of the material with the constraint conditions can be improved effectively. The shape of composite anchor bolts has a significant impact on their uplift resistance. So 
Table 2. The experimental data of different groove depth bolts in pull-out test.

\begin{tabular}{ccccccccccccccc}
\hline Number & R1 & R2 & R3 & R4 & R5 & R6 & R7 & R8 & R9 & R10 & R11 & R12 \\
\hline Groove spacing/mm & 23.15 & 23.15 & 23.15 & 23.15 & 23.15 & 23.15 & 23.15 & 23.15 & 23.15 & 23.15 & 23.15 & 23.15 \\
Groove depth/mm & 0.88 & 0.88 & 0.88 & 2.02 & 2.02 & 2.02 & 3.04 & 3.04 & 3.04 & 3.95 & 3.95 & 3.95 \\
Bolt diameter/mm & 18.64 & 18.64 & 18.64 & 18.64 & 18.64 & 18.64 & 18.64 & 18.64 & 18.64 & 18.64 & 18.64 & 18.64 \\
Anchorage length/mm & $/ 20.40$ & $/ 20.40$ & $/ 20.40$ & $/ 20.40$ & $/ 20.40$ & $/ 20.40$ & $/ 20.40$ & $/ 20.40$ & $/ 20.40$ & $/ 20.4$ & $/ 20.4$ & $/ 20.4$ \\
Temperature/ ${ }^{\circ} \mathrm{C}$ & 22 & 260 & 260 & 260 & 260 & 260 & 260 & 260 & 260 & 260 & 260 & 260 \\
Ultimate tension/kN & 175.6 & 179.5 & 183.9 & 186.5 & 190.3 & 187.6 & 201.2 & 200.9 & 200.6 & 208.9 & 207.8 & 208.1 \\
\hline
\end{tabular}

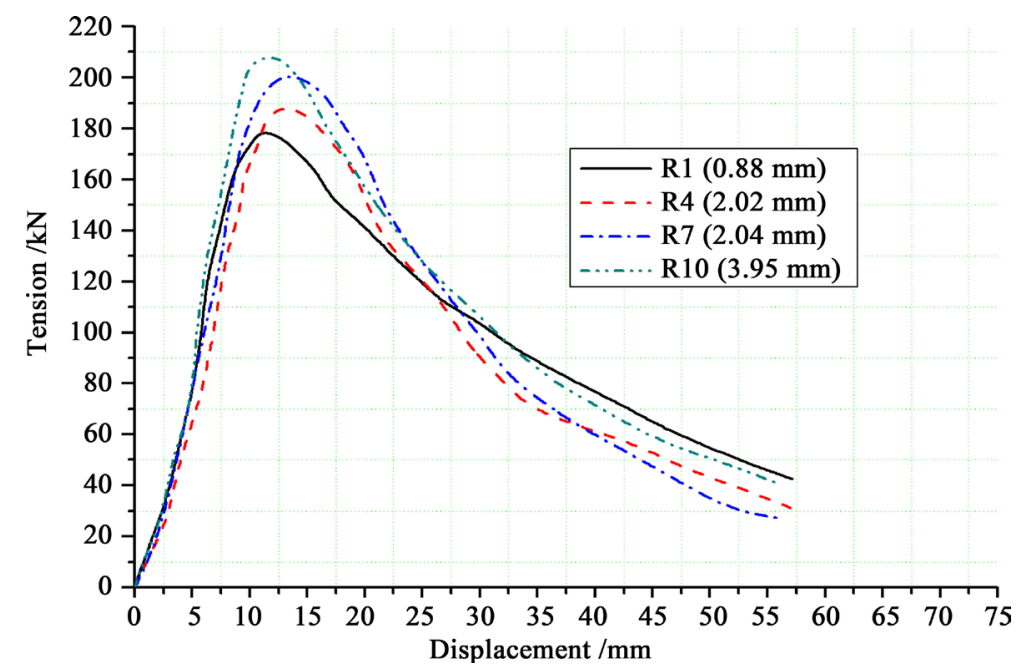

Figure 5. The tension-displacement curve of test-pieces with the change of groove depth.

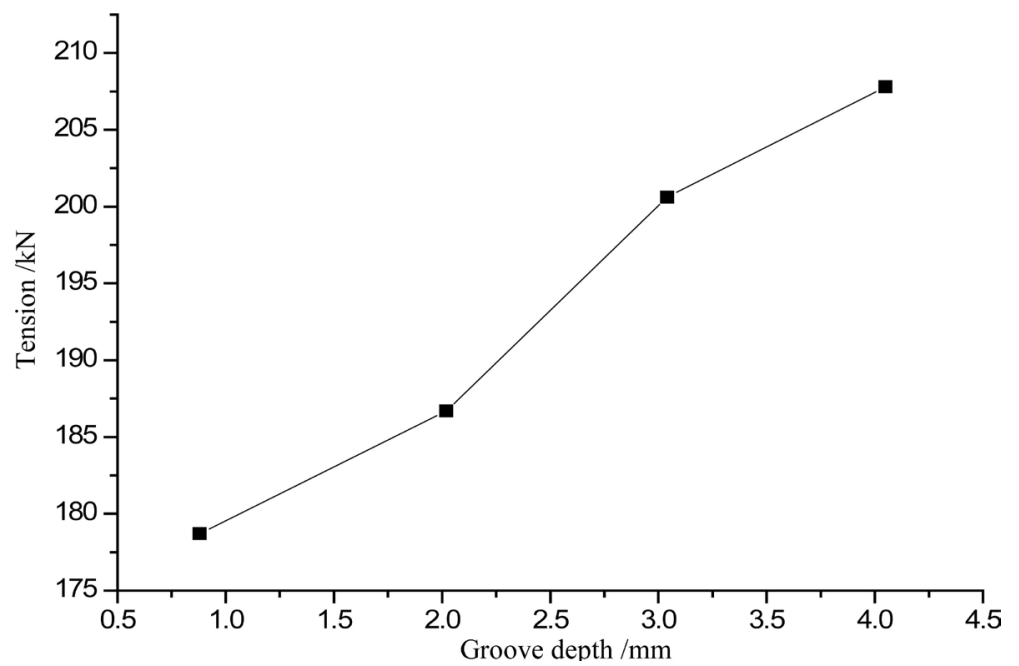

Figure 6. Relationship between tension and groove depth.

it is necessary to study the impact of surficial shape on anchoring performance of composite anchor bolts.

Take a micro segment from the axis of the anchor bolt and analyze its stress state as shown in Figure 7. $\sigma_{r a}(z)$ and $\tau$ stand for respectively the micro segment' normal stress and shear stress while $\sigma_{z}$ stands for the axial stress of the anchoring body. To facilitate the mechanical analysis of the section of anchorage, make the following assumptions: 1) all materials are continuous, homogeneous and isotropic linear elastic body; 2) the 
axial stress $\sigma_{z}$ distributes in the transect of the anchoring agent uniformly; 3) the anchor bolt and the anchoring agent deform simultaneously in the radial direction in the range of elastic deformation.

As shown in Figure 8, $F$ is the tension of the anchor bolt. And then the axial stress of an arbitrary point $M(0$, $0, z)$ on the anchoring agent is

$$
F(z)=F-\int_{0}^{z} 2 \pi r_{a} \tau(z) \mathrm{d} z
$$

The axial strain of $M$ is

$$
\sigma_{z}(z)=\frac{F(z)}{A_{a}}=\frac{F-\int_{0}^{z} 2 \pi r_{a} \tau(z) \mathrm{d} z}{\pi r_{a}^{2}}
$$

In the formula above, $r_{a}$ stands for the radius of the anchoring agent and $A_{a}$ stands for its cross-sectional area.

According to the Hooke's law, the radial strain $\varepsilon_{r a}$ of point $M$ in the anchoring agent is

$$
\varepsilon_{r a}(z)=\frac{1}{E_{a}}\left[v_{2} \sigma_{z}(z)-\left(1-v_{2}\right) \sigma_{r a}(z)\right]
$$

In the formula (3), $v_{2}$ stands for the Poisson ratio of the anchoring agent and $E_{a}$ stands for its elasticity modulus converted.

The shear in the interface meets with the Mohr-Coulomb criterion, so it is

$$
\tau(z)=c+\sigma_{r a}(z) \tan \varphi
$$

Based on the theory of elastic mechanics, the radial strain of radius $r$ in a anchoring agent (whose length is $z$ ) when a circular aperture is loaded a radial stress $\sigma_{r a}(z)$ is

$$
\varepsilon_{r r}(z)=\frac{1+v_{1}}{E} \frac{r_{a}^{2}}{r^{2}} \sigma_{r a}(z)
$$

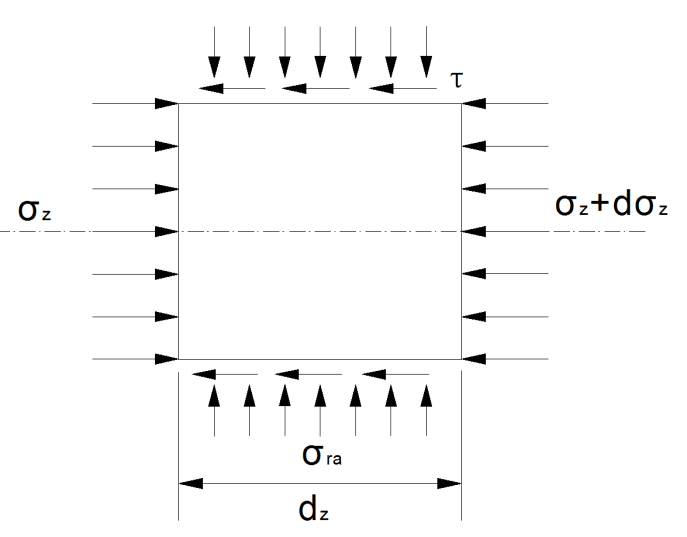

Figure 7. Mechanical analysis on the stress state of the micro segment.

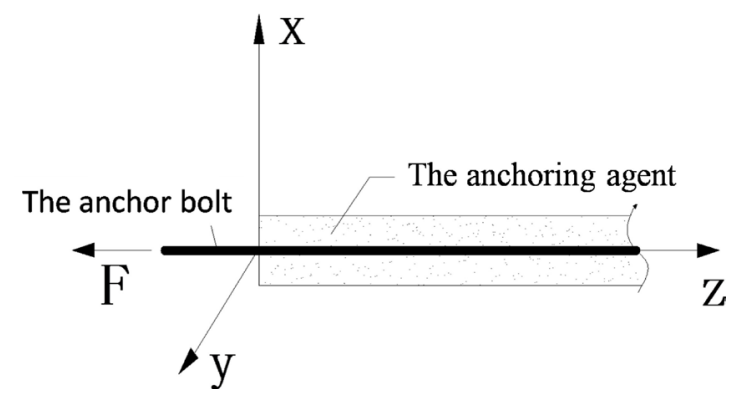

Figure 8. Calculation diagram. 
In the formula (5), $E$ and $v_{1}$ stand for the elasticity modulus and poisson ratio of the anchoring agent with constraint conditions respectively.

On the basis of deformation and coordination conditions,

$$
\left.\varepsilon_{r r}\right|_{r=r_{a}}=\varepsilon_{r a}
$$

Synthesize the formula (3), formula (5) and formula (6). And the compatibility equation of deformation is

$$
\begin{aligned}
& \left(\frac{1-v_{2}}{E_{a}}+\frac{1+v_{1}}{E}\right) \sigma_{r a}(z)=\frac{v_{2}}{E_{a}} \sigma_{z}(z) \\
& \sigma_{r a}(z)=\frac{E v_{2}}{E_{a}\left(1+v_{1}\right)+E\left(1-v_{2}\right)} \sigma_{z}(z)
\end{aligned}
$$

When $K=\frac{E v_{2}}{E_{a}\left(1+v_{1}\right)+E\left(1-v_{2}\right)}$, there is

$$
\sigma_{r a}(z)=K \sigma_{z}(z)
$$

Synthesize the formula (2), formula (4) and formula (9) and there is

$$
\sigma_{r a}(z)=K \frac{\left(F-\int_{0}^{z} 2 \pi r_{a} \tau(z) \mathrm{d} z\right)}{\pi r_{a}^{2}}
$$

A differential equation can be obtained by a simultaneous of formula (4) and formula (10).

$$
\sigma_{r a}^{\prime}(z)=-A \sigma_{r a}(z)-B
$$

In formula (11), $A=\frac{2 K \tan \varphi}{r_{a}}, B=\frac{2 K c}{r_{a}}$.

The general solution of formula (11) is

$$
\sigma_{r a}(z)=\frac{C \exp (-A z)-B}{A}
$$

$C$ is a constant in formula (12).

There is a boundary condition:

$$
\sigma_{z}(z)=\frac{F}{\pi r_{a}^{2}}, \quad z=0
$$

According to the formula (9),

$$
\sigma_{r a}(z)=K \frac{F}{\pi r_{a}^{2}}, \quad z=0
$$

Substitute formula (14) into formula (12), $\quad C=\frac{K F A}{\pi r_{a}^{2}}+B$

The following formulas can be obtained.

$$
\begin{gathered}
\sigma_{r a}(z)=\frac{K F}{\pi r_{a}^{2}} \exp (-A z)+\frac{B(\exp (-A z)-1)}{A} \\
\sigma_{z}(z)=\frac{F}{\pi r_{a}^{2}} \exp (-A z)+\frac{B(\exp (-A z)-1)}{A K} \\
\tau(z)=c+\left(\frac{K F}{\pi r_{a}^{2}} \exp (-A z)+\frac{B(\exp (-A z)-1)}{A}\right) \tan \varphi
\end{gathered}
$$

It can be obtained by formula (16)-(18) that the stress and its distribution between the anchoring agent and the anchor bolt connect with some factors such as the stress of the anchor bolt, the radius, elasticity modulus and 
poisson ratio of the anchoring agent, etc. Therefore, it is effective to enhance the cohesion between anchor bolt and anchoring agent by the method of changing the surficial shape of the anchor bolt. Thereby the anchoring performance can be improved obviously. The analysis above is the same with the experiment result.

\section{Conclusions}

1) As for the groove spacing, the uplift resistance of composite anchor bolts firstly increases and then decreases with the increase of groove spacing. It is reasonable that the groove spacing is designed as $23.15 \mathrm{~mm}$ taking various factors into consideration. The result provides a reference for the surficial treatment to improve the anchoring performance.

2) The anchoring performance of the composite anchor bolt increases with the increase of groove depth. It is reasonable to design the groove depth as $3.95 \mathrm{~mm}$. The mechanical property can be improved by the groove depth. It is a pretty way to make the anchoring performance more advanced.

3) It indicates that the composite anchor bolt has a good overall performance that the resin never breaks away from the inside steel strand during the experiments.

4) On the condition that there is little impact on the strength of extension of the anchor bolt, it is a very effective way to improve the anchoring performance by changing the surficial shape of the anchor bolt which has been confirmed by experiments and theoretical analysis.

\section{References}

[1] Tokumam, M., Namse, T., Mizulani, J., et al. (1995) Development and Construction of Durable Aramid FRP Ground Anchors A1. Taerwe, L., Ed., Proceeding of Second International RILEM Symposium, RILEM, London, 696-703.

[2] Ehsani, M.R., Saadatmanesh, H. and Tao, S. (1993) Bond of GFRP Rebar to Ordinary Strength Concrete. Nanni, A. and Charles, W., Eds., Proceedings of International Symposium: Fiber-Reinforcement for Concrete Structures, Detroit, 1993, 333-346.

[3] Quan, J.W. (2005) A Fast Bracing Construction Technology of Resin Bolting in Xuzhou. Coal Science \& Technology Magazine, 3, 14-16.

[4] Liang, X.M., Zhang, Y.D., Hu, G.Q., et al. (2015) Analysis of Mechanical Properties of Fully Anchored Pre-Stressed Resin Bolts and Their Application. Gold, 36, 38-42.

[5] Li, K.L. (2012) Experimental Study on GFRP Anchor Corrosion Resistance and Bond Durability. Central South University, Changsha.

[6] Zhu, H.C., Rong, G., Xiao, M., et al. (2002) Testing Study on Working Mechanism of Full Grouting Bolt under Tensile Load. Chinese Journal of Rock Mechanics and Engineering, 21, 379-384.

[7] Gao, L. (2007) Experimental Study on Tensile Character and Failure Mechanism of GFRP Bebar. North China University of Water Resources and Electric Power, Zhengzhou.

[8] Hu, J.X. (2012) The Research and Analysis on Anchoring Performance of GFRP Bolt. Central South University, Changsha.

[9] Chen, Y. (2014) Mechanical Analysis on Anchorage Performance of Resin Anchored Bolt. China University of Mining and Technology, Beijing.

[10] Kang, H.P., Cui, Q.L., Hu, B., et al. (2014) Analysis on Anchorage Performances and Affecting Factors of Resin Bolts. Journal of China Coal Society, 39, 1-10.

[11] Shi, J.J., Liu, H.T. and Ma, N.J. (2011) Experiment Study on Mechanics Performances of High Strength Metal Bolt. Coal Engineering, No. 3, 102-104.

[12] Zhan, Y.B., Bi, X.K. and You, C.A. (2006) Numerical Simulation on Stress Distribution in Anchorage Body. Rock and Soil Mechanics, 27, 935-938.

[13] Liu, Y.H. and Yuan, Y. (2010) Experimental Research on Anchorage Performance of Full-Thread GFRP Bonding Anchor Bolts. Chinese Journal of Rock Mechanics and Engineering, 29, 394-400. 